OPEN ACCESS

Edited by:

Farhad Kamali,

Newcastle University, United Kingdom

Reviewed by:

Kotone Matsuyama,

Nippon Medical School, Japan

Zoltán S. Zádori,

Semmelweis University, Hungary

*Correspondence:

Kojiro Takamoto

ko-takamoto@hyo-med.ac.jp

Specialty section:

This article was submitted to

Drugs Outcomes Research

and Policies,

a section of the journal

Frontiers in Pharmacology

Received: 13 January 2021

Accepted: 12 April 2021

Published: 26 April 2021

Citation:

Takamoto K, Sakamoto J, Ito S, Kimura T, Manabe E, Shikata $T$, Asakura M, Ishihara $M$ and Tsujino $T$ (2021) Low Quality of Warfarin Therapy is Associated With Female Gender but Not With Polypharmacy in Patients

With Atrial Fibrillation.

Front. Pharmacol. 12:651799.

doi: 10.3389/fphar.2021.651799

\section{Low Quality of Warfarin Therapy is Associated With Female Gender but Not With Polypharmacy in Patients With Atrial Fibrillation}

\author{
Kojiro Takamoto ${ }^{1,2 *}$, Jun-ichi Sakamoto ${ }^{1,3}$, Satoyasu Ito ${ }^{4}$, Takeshi Kimura ${ }^{3}$, Eri Manabe ${ }^{5}$, \\ Toshiyuki Shikata $^{2}$, Masanori Asakura ${ }^{5}$, Masaharu Ishihara ${ }^{5}$ and Takeshi Tsujino ${ }^{1,4,5}$ \\ ${ }^{1}$ Graduate School of Pharmacy, Hyogo University of Health Sciences, Kobe, Japan, ${ }^{2}$ Hyogo College of Medicine Sasayama \\ Medical Center, Sasayama, Japan, ${ }^{3}$ Department of Pharmacy, Hyogo College of Medicine Hospital, Nishinomiya, Japan, \\ ${ }^{4}$ Department of Pharmacy, School of Pharmacy, Hyogo University of Health Sciences, Kobe, Japan, ${ }^{5}$ Department of \\ Cardiovascular and Renal Medicine, Hyogo College of Medicine, Nishinomiya, Japan
}

Background: We examined the impact of polypharmacy on the quality of the anticoagulation therapy in patients with atrial fibrillation. We also examined the factors that affect the stability of warfarin therapy.

Methods and Results: This retrospective study was conducted using data from 157 consecutive outpatients with atrial fibrillation in a single tertiary referral hospital. Patients who were prescribed warfarin continuously and for whom PT-INR was examined at least three times in a year were included in this study. We examined the quality of warfarin therapy using time in the therapeutic INR range (TTR), percentage of PT-INR determinations in range (PINRR), and the coefficient variation (CV) of PT-INR. We found that the number of prescribed medicines was significantly associated with high BMl and low eGFR, but not with TTR, PINRR, and the coefficient variation of PT-INR in patients with atrial fibrillation. We also found that female gender was independently associated with low PINRR in this study population.

Conclusion: Polypharmacy did not deteriorate the quality of warfarin therapy in patients with atrial fibrillation treated in the tertiary referral hospital. Female gender was an independent predictor of the low quality of warfarin therapy.

Keywords: polypharmacy, atrial fibrillation, warfarin, PINRR, TTR, female gender, sex differences

\section{INTRODUCTION}

Declining fertility rates and increasing life expectancy has led to a rapid increase in the average age of the population; in addition, the incidence of atrial fibrillation (AF) is rapidly increasing in the elderly population (Ohsawa et al., 2005; Inoue et al., 2009). AF is a common arrhythmia and strong risk factor for cardiogenic thromboembolism (Wolf et al., 1991; Feinberg et al., 1995). Appropriate treatment including anticoagulant medication, is needed to prevent cardiogenic thromboembolism (Hart et al., 1998; Connolly et al., 2009; Hori et al., 2012; Kim et al., 2018; Cheng et al., 2019). In the past, the vitamin $\mathrm{K}$ inhibitor warfarin, was the only orally active anticoagulant for prevention of stroke in patients with AF in Japan. However, in recent years, direct oral anticoagulants (DOACs), such as dabigatran, edoxaban, rivaroxaban, and apixaban, have been used widely. DOACs have 
decreased the risk of cardiogenic thromboembolic events and the mortality of patients with AF (Halperin et al., 2014; Halvorsen et al., 2014; Toda Kato et al., 2016; Mandy et al., 2017). However, warfarin is still widely used because DOACs are more expensive than warfarin and cannot be used in patients with impaired renal function. Warfarin is known to interact with many medications, and the effects are different in each individual. It is well known that strict control of the international normalized ratio of prothrombin time (PT-INR) during warfarin therapy is required to ensure not only efficacy but also safety. However, in previous meta-analyses, the quality of anticoagulation control with warfarin was proven to be poor, with an estimated time in the therapeutic INR range (TTR) between 55 and 64\% (van Walraven et al., 2006; Wan et al., 2008; Baker et al., 2009; Cios et al., 2009). Thus, warfarin administration should be refined for the safe and effective treatment of AF patients.

The use of multiple medications, widely referred to as polypharmacy, is a clinical issue in the older population (Hajjar et al., 2007). There is no standard cut-off point with regard to multiple medications, but polypharmacy is usually considered as five or more medications in Japan, in accordance with the Guidelines for Medical Treatment and its Safety in the Elderly 2015 (The Japan Geriatrics Society, 2015). Polypharmacy has been shown to impair adherence to medication. Moreover, the potency of warfarin is known to be affected by concomitant medications. Therefore, polypharmacy could deteriorate the quality of warfarin therapy. In fact, polypharmacy has been shown to be associated with mortality and bleeding complications in patients with AF (Abdelhafiz and Wheeldon, 2008; Proietti et al., 2016). However, it is not fully elucidated whether polypharmacy worsens warfarin control. The examination of the impact of polypharmacy on the stability of warfarin therapy is important for the safe use of warfarin. In this study, we examined how polypharmacy affected the stability of warfarin therapy in patients with AF. We also examined other factors affecting warfarin control.

\section{METHODS}

\section{Population and Data Collection}

This retrospective study was conducted using the data from outpatients with AF visiting the Department of Cardiovascular and Renal Medicine, Hyogo College of Medicine Hospital between April 2013 and March 2014. Patients who were prescribed warfarin continuously and received PT-INR examination at least three times during this period were included in the study. Patients who were admitted to the hospital during this period were excluded. We collected data from their clinical records, including demographics, comorbidity, and medications. Polypharmacy was defined to be prescribed five or more medications regularly in this study period. We used the TTR, the percentage of PT-INR in the therapeutic range (PINRR), and coefficient variation (CV) of PT-INR as index to evaluate the stability of warfarin therapy. TTR was determined using a linear interpolation method between consecutive PT-INR values in each patient as reported by the Rosendaal method
(Rosendaal et al., 1993). Japanese Guidelines for Pharmacotherapy of Atrial Fibrillation recommended that PTINR should be controlled between 2.0 and 3.0 in patients of $<70$ years of age and between 1.6 and 2.6 in those of $\geq 70$ years of age between April 2013 and March 2014 (The Japan Circulation Society, 2014). However, real-world data revealed that PT-INR values in patients of $<70$ years were in the same range as those in patients of $\geq 70$ years of age in Japan (Okumura et al., 2011; Tomita et al., 2013). JCS/JHRS 2020 Guideline on Pharmacotherapy of Cardiac Arrhythmias now recommends that PT-INR should be controlled between 1.6 and 2.6 regardless of age for primary prevention (The Japan Circulation Society/Japanese Heart Rhythm Society Joint Guidelines et al., 2020). Thus, we determined that PT-INR levels were in the therapeutic range when they were between 1.6 and 2.6.

Based on comorbidity information, we calculated each patient's stroke risk predictor score (CHADS2, and CHA2DS2-VASc score) and bleeding risk predictor score (HAS-BLED score) in accordance with previous reports (Gage et al., 2001; Lip et al., 2010; Pisters et al., 2010). We calculate estimated glomerular filtration rate (eGFR) from the Japanese equation: eGFR $\left(\mathrm{ml} / \mathrm{min} / 1.73 \mathrm{~m}^{2}\right)=194 \times$ serum creatinine $-1.094 \times$ age $-0.287(\times 0.739$ if female $)$. Hypertension was defined as a systolic blood pressure of $\geq 140 \mathrm{mmHg}$, a diastolic blood pressure of $\geq 90 \mathrm{mmHg}$, or the use of anti-hypertensive medication. Diabetes mellitus was defined as fasting plasma glucose of $\geq 126 \mathrm{mg} / \mathrm{dl}$, HbAlc of $\geq 6.5 \%$, or the use of antidiabetic medication. Dyslipidemia was defined as low-density lipoprotein cholesterol (LDL-C) of $\geq 140 \mathrm{mg} / \mathrm{dl}$, high-density lipoprotein cholesterol (HDL-C) of $\leq 40 \mathrm{mg} / \mathrm{dl}$, and triglycerides (TG) of $\geq 150 \mathrm{mg} / \mathrm{dl}$, or the use of antidyslipidemia medication. This investigation was approved by the Ethics Committee of Hyogo College of Medicine Hospital (\#1900) and the Ethics Committee of Hyogo University of Health Sciences (\#15009). All analyses were performed in accordance with approved guidelines and regulations. Because this study is a non-invasive retrospective observational study, informed consent of patients was obtained in the opt-out way by disclosing information of the study.

\section{Statistical Analysis}

All statistical analyses were performed with EZR on $R$ Commander Version 1.35 (Saitama Medical Center, Jichi Medical University, Saitama, Japan) (Kanda, 2013), which is a graphical user interface for R (The R Foundation for Statistical Computing, Vienna, Austria). The data were presented as the mean \pm standard deviation (SD) for normally distributed variables, the median (interquartile range) for not normally distributed variables, or the number (percentage) for categorical variables. The differences in categorical variables between groups were assessed using Fisher's exact test. The differences in continuous variables between groups were assessed using unpaired Student's $t$-test for normally distributed variables, or Mann-Whitney's $U$-test for not normally distributed variables. With regard to continuous variables, the correlation between each variable was examined 
TABLE 1 | Clinical characteristics.

\begin{tabular}{|c|c|c|c|c|}
\hline \multicolumn{5}{|c|}{ All } \\
\hline & & NP & PP & $p$-value \\
\hline$N$ & 157 & 32 & 125 & \\
\hline Age (years) & $72.1 \pm 8.7$ & $73.7 \pm 8.3$ & $71.7 \pm 8.7$ & 0.368 \\
\hline $\mathrm{BMl}\left(\mathrm{kg} / \mathrm{m}^{2}\right)$ & $23.6 \pm 3.7$ & $22.5 \pm 4.4$ & $23.9 \pm 3.5$ & 0.144 \\
\hline Male & $121(77.1)$ & $24(75.0)$ & $97(77.6)$ & 0.814 \\
\hline Paroxysmal AF & $60(38.2)$ & $12(37.5)$ & $48(38.4)$ & 1.000 \\
\hline \multicolumn{5}{|l|}{ Comorbid diseases } \\
\hline Heart failure & $51(32.5)$ & $4(12.5)$ & 47 (37.6) & 0.006 \\
\hline Hypertension & $115(73.2)$ & $19(59.4)$ & $96(76.8)$ & 0.072 \\
\hline Diabetes mellitus & $45(28.7)$ & $4(12.5)$ & $41(32.8)$ & 0.028 \\
\hline Dyslipidemia & $54(34.4)$ & $11(34.4)$ & $43(34.4)$ & 1.000 \\
\hline Stroke & $14(8.9)$ & $2(6.3)$ & $12(9.6)$ & 0.737 \\
\hline Ischemic heart disease & $32(20.4)$ & $2(6.3)$ & $30(24.0)$ & 0.027 \\
\hline Peripheral artery disease & $5(3.2)$ & $0(0)$ & $5(4.0)$ & 0.584 \\
\hline Vascular disease & 35 (22.3) & $2(6.3)$ & $33(26.4)$ & 0.016 \\
\hline Abnormal renal function & $1(0.6)$ & $0(0)$ & $1(0.8)$ & 1.000 \\
\hline Abnormal liver function & $3(1.9)$ & $0(0)$ & $3(2.4)$ & 1.000 \\
\hline Bleeding & $36(22.9)$ & $8(25.0)$ & $28(22.4)$ & 0.814 \\
\hline \multicolumn{5}{|l|}{ Laboratory test } \\
\hline WBC $\left(\times 10^{2} / \mu \mathrm{l}\right)$ & $57.2 \pm 15.8$ & $59.6 \pm 20.5$ & $56.5 \pm 14.4$ & 0.345 \\
\hline $\operatorname{RBC}\left(\times 10^{4} / \mu \mathrm{l}\right)$ & $442 \pm 56$ & $449 \pm 53$ & $400 \pm 57$ & 0.483 \\
\hline $\mathrm{Hb}(\mathrm{g} / \mathrm{dl})$ & $13.7 \pm 1.7$ & $14.0 \pm 1.6$ & $13.6 \pm 1.7$ & 0.220 \\
\hline $\mathrm{Ht}(\%)$ & $41.1 \pm 4.7$ & $42.0 \pm 4.4$ & $40.9 \pm 4.8$ & 0.227 \\
\hline Plt $\left(\times 10^{4} / \mu \mathrm{l}\right)$ & $17.6 \pm 5.2$ & $18.6 \pm 5.4$ & $17.4 \pm 5.2$ & 0.269 \\
\hline $\mathrm{Cr}(\mathrm{mg} / \mathrm{dl})$ & $1.0 \pm 0.3$ & $0.9 \pm 0.2$ & $1.0 \pm 0.4$ & 0.021 \\
\hline eGFR $\left(\mathrm{ml} / \mathrm{min} / 1.73 \mathrm{~m}^{2}\right)$ & $60.7 \pm 18.4$ & $67.3 \pm 18.0$ & $59.1 \pm 18.2$ & 0.028 \\
\hline AST $(U / L)$ & $24.2 \pm 8.6$ & $24.3 \pm 7.9$ & $24.1 \pm 8.7$ & 0.905 \\
\hline ALT (U/L) & $18.7 \pm 7.8$ & $19.0 \pm 7.3$ & $18.6 \pm 8.0$ & 0.796 \\
\hline $\mathrm{CHADS}_{2}$ score & $2(1,3)$ & $1(1,2)$ & $2(1,3)$ & 0.002 \\
\hline 0 & $15(9.6)$ & $5(15.6)$ & $10(8.0)$ & \\
\hline 1 & 49 (31.2) & $14(43.8)$ & $35(28.0)$ & \\
\hline 2 & $44(28.0)$ & 10 (31.3) & $34(27.2)$ & \\
\hline 3 & 35 (22.3) & $3(9.4)$ & $32(25.6)$ & \\
\hline 4 & $9(5.7)$ & $0(0)$ & $9(7.2)$ & \\
\hline 5 & $3(1.9)$ & $0(0)$ & $3(2.4)$ & \\
\hline 6 & $2(1.3)$ & $0(0)$ & $2(1.6)$ & \\
\hline $\mathrm{CHA}_{2} \mathrm{DS}_{2}$-VASc score & $2(2,4)$ & $2(1.8,3)$ & $3(2,4)$ & 0.133 \\
\hline 0 & $6(3.8)$ & $1(3.1)$ & $5(4.0)$ & \\
\hline 1 & $32(20.4)$ & 7 (21.9) & $25(20.0)$ & \\
\hline 2 & $43(27.4)$ & $13(40.6)$ & $30(24.0)$ & \\
\hline 3 & $26(16.6)$ & $4(12.5)$ & $22(17.6)$ & \\
\hline 4 & $28(17.8)$ & $6(18.8)$ & $22(17.6)$ & \\
\hline 5 & $13(8.3)$ & $1(3.1)$ & $12(9.6)$ & \\
\hline 6 & $6(3.8)$ & $0(0)$ & $6(4.8)$ & \\
\hline 7 & $2(1.3)$ & $0(0)$ & $2(1.6)$ & \\
\hline 8 & $1(0.6)$ & $0(0)$ & $1(0.8)$ & \\
\hline HAS-BLED score & $1(0,2)$ & $0(0,1)$ & $1(0,2)$ & 0.011 \\
\hline 0 & 69 (43.9) & $20(62.5)$ & 49 (39.2) & \\
\hline 1 & $55(35.0)$ & $9(28.1)$ & $46(36.8)$ & \\
\hline 2 & 26 (16.6) & $3(9.4)$ & $23(18.4)$ & \\
\hline 3 & $7(4.5)$ & $0(0)$ & 7 (5.6) & \\
\hline Mean of PT-INR & $2.01 \pm 0.27$ & $2.02 \pm 0.26$ & $2.01 \pm 0.27$ & 0.807 \\
\hline TTR (\%) & $84(68,97)$ & $83(72,99)$ & $85(67,96)$ & 0.595 \\
\hline PINRR (\%) & $78(60,90)$ & $78(62,100)$ & $78(60,90)$ & 0.670 \\
\hline PINROR (\%) & $0(0,17)$ & $0(0,15)$ & $0(0,17)$ & 0.671 \\
\hline PINRBR (\%) & $11(0,27)$ & $0(0,28)$ & $12(0,27)$ & 0.444 \\
\hline CV of PT-INR & $0.153 \pm 0.080$ & $0.147 \pm 0.069$ & $0.154 \pm 0.083$ & 0.632 \\
\hline Dose of warfarin & $2.7(2,3.5)$ & $3(2.5,3.625)$ & $2.5(2,3)$ & 0.084 \\
\hline Use of granule formulation of warfarin & $4(2.5)$ & $0(0)$ & $4(3.2)$ & 0.583 \\
\hline Number of warfarin dose changes & $0(0,1)$ & $0(0,1)$ & $0(0,1)$ & 0.153 \\
\hline \multicolumn{5}{|l|}{ Medications } \\
\hline Number of prescribed drugs & $7(5,9)$ & $3(3,4)$ & $8(6,10)$ & $<0.001$ \\
\hline $\mathrm{ARB}$ & $78(49.7)$ & $9(28.1)$ & $69(55.2)$ & 0.015 \\
\hline ACEl & $28(17.8)$ & $1(3.1)$ & $27(21.6)$ & 0.017 \\
\hline
\end{tabular}

(Continued on following page) 
TABLE 1 | (Continued) Clinical characteristics.

\begin{tabular}{|c|c|c|c|c|}
\hline \multicolumn{5}{|c|}{ All } \\
\hline & & NP & PP & $p$-value \\
\hline Calcium channel blocker & 47 (29.9) & $3(9.4)$ & $44(35.2)$ & 0.004 \\
\hline$\beta$-blocker & $111(70.7)$ & $19(59.4)$ & $92(73.6)$ & 0.125 \\
\hline Antiplatelet agent & $46(29.3)$ & $0(0)$ & $46(36.8)$ & $<0.001$ \\
\hline NSAIDs & 5 (3.2) & $0(0)$ & $5(4.0)$ & 0.584 \\
\hline PPI & $70(44.6)$ & $9(28.1)$ & $61(48.8)$ & 0.069 \\
\hline $\mathrm{H}_{2}$-blocker & $17(10.8)$ & $2(6.3)$ & $15(12.0)$ & 0.527 \\
\hline Statin & $65(41.4)$ & $5(15.6)$ & $60(48.0)$ & 0.001 \\
\hline Oral hypoglycemic agent & $26(16.6)$ & $2(6.3)$ & $24(19.2)$ & 0.109 \\
\hline Insulin & $9(5.7)$ & $0(0)$ & $9(7.2)$ & 0.206 \\
\hline Antianxiety or hypnotic & $21(13.4)$ & $2(6.3)$ & $19(15.2)$ & 0.252 \\
\hline Medications potentiating the action of warfarin & $90(57.3)$ & $7(21.9)$ & $83(66.4)$ & $<0.001$ \\
\hline Allopurinol & $35(22.3)$ & $2(6.3)$ & $33(26.4)$ & 0.016 \\
\hline Rosuvastatin & $23(14.6)$ & $2(6.3)$ & $21(16.8)$ & 0.168 \\
\hline Levothyroxine & $14(8.9)$ & $2(6.3)$ & $12(9.6)$ & 0.737 \\
\hline Others & $50(31.8)$ & $3(9.4)$ & $47(37.6)$ & 0.002 \\
\hline Medications weakening the effect of warfarin & $9(5.7)$ & $0(0)$ & $9(7.2)$ & 0.206 \\
\hline
\end{tabular}

The data are presented as mean \pm SD for normally distributed variables, median (first quartile, third quartile) for not normally distributed variables, or the number (percentage) for categorical variables. We defined vascular disease as prior myocardial infarction, peripheral artery disease, or aortic plaque, according to CHA2DS2-VASC score (Lip et al., 2010). We also defined bleeding as bleeding history or bleeding tendency (bleeding predisposition and anemia) according to HAS-BLED score (Pisters et al., 2010) Differences in categorical variables between the NP group (number of prescribed drugs $\leq 4$ ) and the PP group (number of prescribed drugs $\geq 5$ ) were assessed using Fisher's exact test. Differences in continuous variables between the NP group and the PP group were assessed using unpaired Student's t-test for normally distributed variables, or Mann-Whitney U-test for not normally distributed variables. ACEl, angiotensinconverting enzyme inhibitor; ARB, angiotensin receptor blocker; BMI, body mass index; Cr, serum creatinine; eGFR, estimated glomerular filtration rate; $\mathrm{H}_{2}$-blocker, histamine type 2 receptor blocker; Hb, hemoglobin; Ht, hematocrit; NP, non-polypharmacy; NSAID, non-steroidal anti-inflammatory drug; PINRBR, percentage of PT-INR determinations below range; PINROR, percentage of PT-INR determinations over range; PINRR, percentage of PT-INR determinations in range; PIt, platelet; PP, polypharmacy; PPI, proton pump inhibitor; PT-INR, international normalized ratio of prothrombin time; RBC, red blood cells; TTR, time in therapeutic range; WBC, white blood cells.

TABLE 2 | Correlation between the clinical factors and the number of the prescribed drugs.

\begin{tabular}{lcc}
\hline Factor & $\boldsymbol{\rho}$ & $\boldsymbol{p}$-value \\
\hline $\mathrm{CHADS}_{2}$ score & 0.440 & $<0.001$ \\
HAS-BLED score & 0.429 & $<0.001$ \\
eGFR & -0.307 & $<0.001$ \\
$\mathrm{Cr}$ & 0.303 & $<0.001$ \\
$\mathrm{CHA}_{2} \mathrm{DS}_{2}$-VASc score & 0.275 & $<0.001$ \\
$\mathrm{BMI}$ & 0.182 & 0.030 \\
$\mathrm{AST}$ & -0.180 & 0.027 \\
TTR & -0.097 & 0.234 \\
PINRR & -0.064 & 0.427 \\
CV of PT-INR & -0.042 & 0.599
\end{tabular}

Correlations between each variable were examined using Spearman's rank correlation coefficient rho ( $\rho)$. Abbreviations as in Table 1.

using Spearman's rank correlation coefficient. The factors that were independently associated with the number of drugs were analyzed using linear regression analysis. Factors with $p<0.10$ in Spearman's rank correlation coefficient were selected as independent factors in the multivariate analysis.

\section{RESULTS}

\section{Study Population}

This retrospective study was conducted using data from 157 outpatients with non-valvular AF. The characteristics of the study population are shown in Table 1. The median of the number of prescribed drugs in the whole study population was seven, and
TABLE 3 | Multivariate factors associated with the number of the prescribed drugs.

\begin{tabular}{lcc}
\hline Factor & $\boldsymbol{\beta}$ & $\boldsymbol{p}$-value \\
\hline eGFR & -0.065 & $<0.001$ \\
BMI & 0.253 & 0.001 \\
AST & -0.052 & 0.119
\end{tabular}

Factors which were independently associated with the number of the prescribed drugs were examined using linear regression analysis. Abbreviations as in Table 1.

TABLE 4 | Correlation with PINRR.

\begin{tabular}{lcc}
\hline Factor & $\boldsymbol{\rho}$ & $\boldsymbol{p}$-value \\
\hline HAS-BLED score & -0.302 & $<0.001$ \\
RBC & 0.176 & 0.034 \\
Ht & 0.164 & 0.049 \\
Hb & 0.141 & 0.091
\end{tabular}

Correlations between each variable were examined using Spearman's rank correlation coefficient rho ( ). Abbreviations as in Table 1.

125 patients (79.6\%) were using five or more prescription drugs regularly. The average age of the study population was $72.1 \pm$ 8.7 years of age and there were 121 male patients $(77.1 \%)$. The number of patients with CHADS2 score more than or equal to 2 was 93 (59.2\%). The number of patients with CHA2DS2-VASc score more than or equal to 2 was $119(75.8 \%)$. The number of patients with HAS-BLED score more than or equal to 3 was 7 (4.5\%). We evaluated the quality of warfarin therapy with TTR and PINRR. The median TTR was $84 \%$ and the median PINRR was $78 \%$. The mean \pm SD TTR was $79.5 \pm 20.7 \%$, which was 

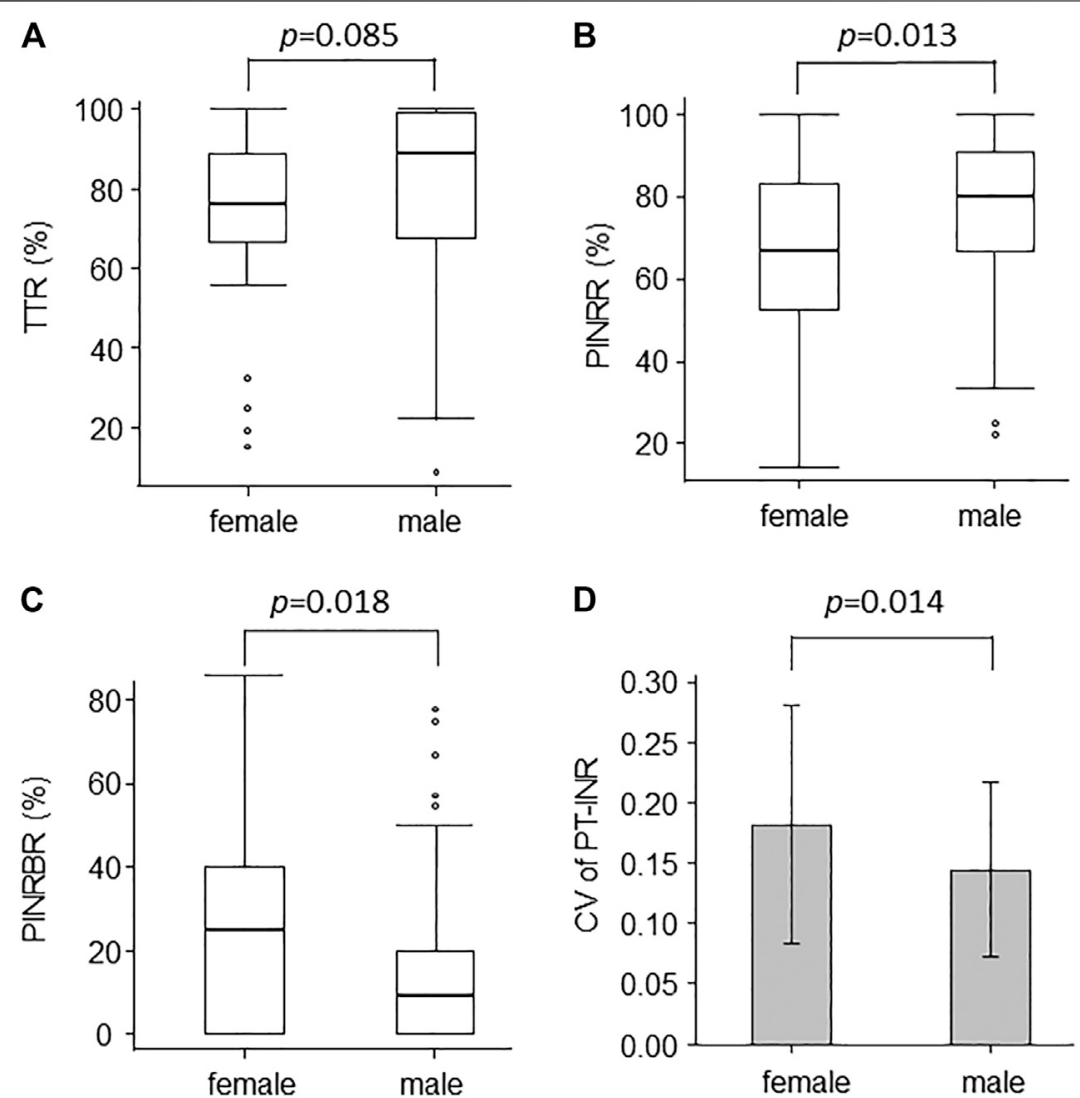

FIGURE 1 | Box plots of (A) TTR, (B) PINRR, and (C) PINRBR show the difference between the quality of warfarin control in male and female patients. Box, interquartile range; horizontal line within box, median; whiskers, smallest and largest non-outlier values; open circles, outliers. Bar chart of (D) shows the CV of PT-INR in male and female patients (mean \pm standard deviation). TTR, time in therapeutic range; PINRR, percentage of PT-INR determinations in range; PINRBR, percentage of PT-INR determinations below range; PT-INR, international normalized ratio of prothrombin time.

comparable with previous reports from Japan (Okumura et al., 2011; Tomita et al., 2013). PT-INR values in patients of $<70$ years of age were almost the same as those in patients of $\geq 70$ years of age in our study population ( $<70$ years of age vs. $\geq 70$ years of age; $2.03 \pm$ 0.27 vs. $1.99 \pm 0.27, p=0.371$ ). Thus, it was reasonable to calculate PINRR as the percentage of PT-INR between 1.6 and 2.6 in all patients as previously reported in Japan (Okumura et al., 2011; Tomita et al., 2013). Medications potentiating the action of warfarin were prescribed in 90 patients (57.3\%), and medications weakening the effects of warfarin (mostly glucocorticoid formulations) were prescribed in nine patients $(5.7 \%)$.

\section{Factors Correlated With the Number of Prescribed Drugs}

In the univariate analyses, the number of the prescribed drugs was positively correlated with HAS-BLED score, CHADS2 score, CHA2DS2-VASc score, Cr, and BMI, and negatively correlated with eGFR and AST (Table 2). The TTR, PINRR, and CV of PTINR were not significantly correlated with the number of the prescribed drugs. Factors with $p<0.10$ in Spearman's rank correlation coefficient were selected as independent factors in the multivariate analysis (i.e., eGFR, BMI, and AST). HAS-BLED score,
TABLE 5 | Multivariate factors associated with PINRR.

\begin{tabular}{lcc}
\hline Factor & $\boldsymbol{\beta}$ & $\boldsymbol{p}$-value \\
\hline Male & 8.978 & 0.033 \\
$\mathrm{Hb}$ & 1.123 & 0.281
\end{tabular}

Factors which were independently associated with PINRR were examined using linear regression analysis. Abbreviations as in Table 1.

CHADS2 score, and CHA2DS2-VASc score were omitted from independent variables because of collinearity. In the multivariate analysis, independent variables that were significantly correlated with the number of prescribed drugs were eGFR and BMI (Table 3).

\section{Factors Associated With PT-INR Stability}

We examined factors associated with TTR and PINRR. TTR was negatively correlated with HAS-BLED score $(\rho=-0.266, p<$ 0.001 ). No factors showed a positive correlation with TTR. TTR tended to be lower in female patients, but the difference was not statistically significant (Figure 1A). PINRR was positively correlated with $\mathrm{RBC}$ and $\mathrm{Ht}$, and negatively correlated with HAS-BLED score (Table 4). PINRR was significantly lower in female patients than in male patients (Figure 1B). Factors with 
$p<0.10$ in Spearman's rank correlation coefficient or MannWhitney $U$-test were selected as independent factors in the multivariate analysis (i.e. gender and hemoglobin). HAS-BLED score was omitted from independent variables because poor warfarin control is one of the factors impacting HAS-BLED score. In the multivariate analysis, the independent variable that was significantly correlated with PINRR was gender (Table 5). However, there was no difference in the dose of warfarin between male and female patients (data not shown). There were no differences in CHADS2 score $(p=0.493$, MannWhitney's $U$-test), HAS-BLED score ( $p=0.509$, Mann-Whitney's $U$-test), and the rate of polypharmacy ( $p=0.814$, Fisher's exact test) between the female and male patients.

The mean of PT-INR was significantly lower (female vs. male patients; $1.93 \pm 0.26$ vs. $2.03 \pm 0.27, p=0.035$ ) and the percentage of PT-INR determinations below the range was higher in female patients than in male patients (Figure 1C). These findings suggested that female patients tended to be undertreated.

Next, we examined factors that were associated with the CV of PT-INR. The CV of PT-INR was larger in female patients than in male patients (Figure 1D). The rate of patients who received a change in warfarin dose tended to be higher in female patients than in male patients (female vs. male patients; 55.6 vs. $37.2 \%, p=0.056$ ). Thus, the difficulty in achieving stable warfarin control was thought to be the cause of undertreatment in female patients.

\section{DISCUSSION}

We searched for factors that affected the quality of anticoagulant therapy with warfarin. Especially, we were interested in the impact of polypharmacy on TTR, PINRR, and the CV of PTINR, because some previous studies suggested that polypharmacy is associated with thrombosis or bleeding in patients treated with warfarin. Focks et al. showed that polypharmacy is associated with stroke and major bleeding in patients with AF (Focks et al., 2016). However, they did not determine the quality of warfarin therapy in their population. Thus, we examined whether polypharmacy deteriorated the quality of anticoagulant therapy with warfarin. In our study, polypharmacy did not affect the stability of warfarin therapy. The stability of warfarin therapy was also not related to the number of medications that were known to affect the potency of warfarin. Our results are consistent with the substudy of the Hokusai-VTE trial. Vanassche et al. have shown that polypharmacy is associated with increased recurrence of venous thromboembolism (VTE) but not with poor TTR in VTE patients taking warfarin (Vanassche et al., 2018). The deleterious effect of polypharmacy on the quality of warfarin therapy was not observed in our study as with their study, even though our study population was older and was taking a higher number of medications, which should result in poorer adherence to medication than in their study population. The quality of warfarin therapy may be resistant to poor adherence induced by polypharmacy because its effect is long-lasting. The duration of action of a single dose of racemic warfarin is 2-5 days (BristolMyers Squibb Company, 2011). A few incidences of forgetting to take warfarin might not induce the clinically significant variation in PT-INR. As another reason, the patients may be highly motivated for treatment and well educated about the importance of anticoagulant therapy because our study was conducted in the tertiary referral hospital. Patients who were included in a multicenter randomized controlled study may also be well motivated and educated. Therefore, polypharmacy may not deteriorate adherence in such patients. Further study is needed to determine whether this result is generalizable, especially to patients with frailty, in whom polypharmacy may have a deleterious effect on adherence.

Next, we investigated which factors affected the stability of warfarin therapy. The factors related to the stability of warfarin therapy was gender. Female gender is known to be associated with poor outcomes in patients with AF (Stewart et al., 2002; Friberg et al., 2004). However, it remains unknown why female patients experience a high incidence of stroke. Many studies have reported that TTR tend to be lower in female patients than in male patients with AF (Gomberg et al., 2006; Sullivan et al., 2012; Arbring et al., 2013; Tomita et al., 2013; Abohelaika et al., 2016; García-Sempere et al., 2019). Thus, in SAMe-TT2R2, a scoring system to assess the likelihood of poor INR control among patients with AF receiving warfarin therapy, female gender is one of the factors (Lip et al., 2016). However, to the best of our knowledge, no studies have shown why female gender is associated with the low quality of warfarin therapy. We found that female patients tended to be undertreated. The lower mean values of PT-INR and the higher percentage of PT-INR determinations below range suggested that underdosing of warfarin caused low PINRR in female patients. However, it should be considered why female patients tended to be undertreated. There were no differences in CHADS2 score, HASBLED score, and the rate of polypharmacy between the female and male subgroups. Thus, the risk of stroke, the risk of bleeding, and the number of concomitant diseases were similar in both gender groups and could not explain the poor INR control in female patients. We found that the CV of PT-INR was larger and the proportion of patients who received changes in warfarin dose tended to be higher in female patients than in male patients. Thus, achieving stable warfarin control appears to be more difficult in female patients than in male patients. Instability in warfarin control may result in cause undertreatment in female patients because doctors may tend to select a dose to avoid bleeding rather than thromboembolism. We tried to elucidate why warfarin control was more varied in female patients. However, we did not identify any meaningful findings. In our study population, the age was higher and body weight was lower in female patients than in male patients, but age and body weight were not associated with TTR, PINRR, and the CV of PT-INR. Further studies are necessary to elucidate the mechanisms for the poor quality of warfarin control in female patients. Anyway, we should be more careful to the quality of warfarin control in female patients with AF. Most patients in our study population were prescribed the tablet formulation of warfarin and received dose adjustment in increments of $0.5 \mathrm{mg}$. Fine tuning of warfarin dosage using granule formulation may help to improve the quality of warfarin therapy. It may be better to change from warfarin to DOACs more aggressively in female patients when economically viable. 
There are several limitations in this study. First, the sample size is small. Specifically, the proportion of patient without polypharmacy is small. The proportion of female is also small. Second, the well-known factor contributing to INR instability is dietary intake of Vitamin $\mathrm{K}$ containing foods. This data was not available in this study.

\section{CONCLUSION}

Polypharmacy did not deteriorate the quality of warfarin therapy in patients with AF treated in a tertiary referral hospital. Female gender was an independent predictor of the lower quality of warfarin therapy.

\section{DATA AVAILABILITY STATEMENT}

The raw data supporting the conclusions of this article will be made available by the authors, without undue reservation.

\section{REFERENCES}

Abdelhafiz, A. H., and Wheeldon, N. M. (2008). Risk Factors for Bleeding during Anticoagulation of Atrial Fibrillation in Older and Younger Patients in Clinical Practice. Am. J. Geriatr. Pharmacother. 6, 1-11. doi:10.1016/j.amjopharm.2008. 03.005

Abohelaika, S., Wynne, H., Avery, P., Robinson, B., Kesteven, P., and Kamali, F. (2016). Impact of Age on Long-Term Anticoagulation and How Gender and Monitoring Setting Affect it: Implications for Decision Making and Patient Management. Br. J. Clin. Pharmacol. 82, 1076-1083. doi:10.1111/bcp.13046

Arbring, K., Uppugunduri, S., and Lindahl, T. L. (2013). Comparison of Prothrombin Time (INR) Results and Main Characteristics of Patients on Warfarin Treatment in Primary Health Care Centers and Anticoagulation Clinics. BMC Health Serv. Res. 13, 85. doi:10.1186/1472-6963-13-85

Baker, W. L., Cios, D. A., Sander, S. D., and Coleman, C. I. (2009). Meta-analysis to Assess the Quality of Warfarin Control in Atrial Fibrillation Patients in the United States. J. Manag. Care Pharm. 15, 244-252. doi:10.18553/jmcp.2009.15. 3.244

Bristol-Myers Squibb Company (2011). COUMADIN Package Insert. Available at: https://www.accessdata.fda.gov/drugsatfda_docs/label/2011/009218s107lbl.pdf (Accessed March 20, 2021).

Cheng, C. M., Lin, C. H., Chou, P., and Jong, G. P. (2019). Antithrombotic Treatment May Reduce Mortality Among New-Onset Atrial Fibrillation Patients with Gray-Zone Risk of Stroke. Int. Heart J. 60, 303-309. doi:10. 1536/ihj.18-174

Cios, D. A., Baker, W. L., Sander, S. D., Phung, O. J., and Coleman, C. I. (2009). Evaluating the Impact of Study-Level Factors on Warfarin Control in U.S.based Primary Studies: A Meta-Analysis. Am. J. Health Syst. Pharm. 66, 916-925. doi:10.2146/ajhp080507

Connolly, S. J., Ezekowitz, M. D., Yusuf, S., Eikelboom, J., Oldgren, J., Parekh, A., et al. (2009). Dabigatran versus Warfarin in Patients with Atrial Fibrillation. $N$. Engl. J. Med. 361, 1139-1151. doi:10.1056/NEJMoa0905561

Feinberg, W. M., Blackshear, J. L., Laupacis, A., Kronmal, R., and Hart, R. G. (1995). Prevalence, Age Distribution, and Gender of Patients with Atrial Fibrillation: Analysis and Implications. Arch. Intern. Med. 155, 469-473.

Focks, J. J., Brouwer, M. A., Wojdyla, D. M., Thomas, L., Lopes, R. D., and Washam, J. B. (2016). Polypharmacy and Effects of Apixaban versus Warfarin in Patients with Atrial Fibrillation: Post Hoc Analysis of the ARISTOTLE Trial. BMJ 353, i2868. doi:10.1136/bmj.i2868

Friberg, J., Scharling, H., Gadsbøll, N., Truelsen, T., and Jensen, G. B. (2004). Comparison of the Impact of Atrial Fibrillation on the Risk of Stroke and Cardiovascular Death in Women versus Men (The Copenhagen City Heart Study). Am. J. Cardiol. 94, 889-894. doi:10.1016/j.amjcard.2004.06.023

\section{ETHICS STATEMENT}

This investigation was approved by the Ethics Committee of Hyogo College of Medicine Hospital (\#1900) and the Ethics Committee of Hyogo University of Health Sciences (\#15009). All analyses were performed in accordance with approved guidelines and regulations. Because this study is a noninvasive retrospective observational study, informed consent of patients was obtained in the opt-out way by disclosing information of the study.

\section{AUTHOR CONTRIBUTIONS}

KT and TT designed the study. KT, TT, JS, SI, TK, EM, and TS corrected and analyzed the data. MA, MI, and TT supervised the study. KT and TT wrote the manuscript, and all authors read and approved the final version of manuscript.

Gage, B. F., Waterman, A. D., Shannon, W., Boechler, M., Rich, M. W., and Radford, M. J. (2001). Validation of Clinical Classification Schemes for Predicting Stroke: Results from the National Registry of Atrial Fibrillation. JAMA 285, 2864-2870. doi:10.1001/jama.285.22.2864

García-Sempere, A., Hurtado, I., Bejarano, Q. D., Rodríguez, B. C., Santa, A. Y., Peiró, S., et al. (2019). Quality of INR Control and Switching to Non-vitamin K Oral Anticoagulants between Women and Men with Atrial Fibrillation Treated with Vitamin K Antagonists in Spain. A Population-Based, Real-World Study. PLoS One 14, e0211681. doi:10.1371/journal.pone.0211681

Gomberg, M. M., Wenger, N. K., Feyzi, J., Lengyel, M., Volgman, A. S., Petersen, P., et al. (2006). Anticoagulation in Women with Non-valvular Atrial Fibrillation in the Stroke Prevention Using an Oral Thrombin Inhibitor (SPORTIF) Trials. Eur. Heart J. 27, 1947-1953. doi:10.1093/eurheartj/ehl103

Hajjar, E. R., Cafiero, A. C., and Hanlon, J. T. (2007). Polypharmacy in Elderly Patients. Am. J. Geriatr. Pharmacother. 5, 345-351. doi:10.1016/j.amjopharm. 2007.12.002

Halperin, J. L., Hankey, G. J., Wojdyla, D. M., Piccini, J. P., Lokhnygina, Y., Patel, M. R., et al. (2014). Efficacy and Safety of Rivaroxaban Compared with Warfarin Among Elderly Patients with Nonvalvular Atrial Fibrillation in the Rivaroxaban once Daily, Oral, Direct Factor Xa Inhibition Compared with Vitamin K Antagonism for Prevention of Stroke and Embolism Trial in Atrial Fibrillation (ROCKET AF). Circulation 130, 138-146. doi:10.1161/ CIRCULATIONAHA.113.005008

Halvorsen, S., Atar, D., Yang, H., De Caterina, R., Erol, C., Garcia, D., et al. (2014). Efficacy and Safety of Apixaban Compared with Warfarin According to Age for Stroke Prevention in Atrial Fibrillation: Observations from the ARISTOTLE Trial. Eur. Heart J. 35, 1864-1872. doi:10.1093/eurheartj/ehu046

Hart, R. G., Sherman, D. G., Easton, J. D., and Cairns, J. A. (1998). Prevention of Stroke in Patients with Nonvalvular Atrial Fibrillation. Neurology 51, 674-681. doi:10.1212/wnl.51.3.674

Hori, M., Matsumoto, M., Tanahashi, N., Momomura, S., Uchiyama, S., Goto, S., et al. (2012). Rivaroxaban vs. Warfarin in Japanese Patients with Atrial Fibrillation. The JROCKET AF Study. Circ. J. 76, 2104-2111. doi:10.1253/ circj.cj-12-0454

Inoue, H., Fujiki, A., Origasa, H., Ogawa, S., Okumura, K., Kubota, I., et al. (2009). Prevalence of Atrial Fibrillation in the General Population of Japan: An Analysis Based on Periodic Health Examination. Int. J. Cardiol. 137, 102-107. doi:10.1016/j.ijcard.2008.06.029

Kanda, Y. (2013). Investigation of the Freely Available Easy-To-Use Software 'EZR' for Medical Statistics. Bone Marrow Transpl. 48, 452-458. doi:10.1038/bmt. 2012.244

Kim, I. S., Kim, H. J., Kim, T. H., Uhm, J. S., Joung, B., Lee, M. H., et al. (2018). Nonvitamin K Antagonist Oral Anticoagulants Have Better Efficacy and Equivalent Safety Compared to Warfarin in Elderly Patients with Atrial Fibrillation: A 
Systematic Review and Meta-Analysis. J. Cardiol. 72, 105-112. doi:10.1016/j. jjcc.2018.01.015

Lip, G. Y. H., Nieuwlaat, R., Pisters, R., Lane, D. A., and Crijns, H. J. G. M. (2010). Refining Clinical Risk Stratification for Predicting Stroke and Thromboembolism in Atrial Fibrillation Using a Novel Risk Factor-Based Approach: the Euro Heart Survey on Atrial Fibrillation. Chest 137, 263-272. doi:10.1378/chest.09-1584

Lip, G. Y. H., Potpara, T., Boriani, G., and Blomström, L. C. (2016). A Tailored Treatment Strategy: a Modern Approach for Stroke Prevention in Patients with Atrial Fibrillation. J. Intern. Med. 279, 467-476. doi:10.1111/joim.12468

Mandy, N. L., John, W. E., Michiel, C., Lars, W., Salim, Y., Michael, E., et al. (2017). Effects of Dabigatran According to Age in Atrial Fibrillation. Heart 103, 1015-1023. doi:10.1136/heartjnl-2016-310358

Ohsawa, M., Okayama, A., Sakata, K., Kato, K., Itai, K., Onoda, T., et al. (2005). Rapid Increase in Estimated Number of Persons with Atrial Fibrillation in Japan: An Analysis from National Surveys on Cardiovascular Diseases in 1980, 1990 and 2000. J. Epidemiol. 15, 194-196. doi:10.2188/jea.15.194

Okumura, K., Komatsu, T., Yamashita, T., Okuyama, Y., Harada, M., Konta, Y., et al. (2011). Time in the Therapeutic Range during Warfarin Therapy in Japanese Patients with Non-valvular Atrial Fibrillation: A Multicenter Study of its Status and Influential Factors. Circ. J. 75, 2087-2094. doi:10.1253/circj.cj-11-0350

Pisters, R., Lane, D. A., Nieuwlaat, R., Vos, C. B., Crijns, H. J. G. M., and Lip, Gregory. Y. H. (2010). A Novel User-Friendly Score (HAS-BLED) to Assess 1year Risk of Major Bleeding in Patients with Atrial Fibrillation: the Euro Heart Survey. Chest 138, 1093-1100. doi:10.1378/chest.10-0134

Proietti, M., Raparelli, V., Olshansky, B., and Lip, G. Y. (2016). Polypharmacy and Major Adverse Events in Atrial Fibrillation: Observations from the AFFIRM Trial. Clin. Res. Cardiol. 105, 412-420. doi:10.1007/s00392-015-0936-y

Rosendaal, F. R., Cannegieter, S. C., van der Meer, F. J., and Briët, E. (1993). A Method to Determine the Optimal Intensity of Oral Anticoagulant Therapy. Thromb. Haemost. 69, 236-239.

Stewart, S., Hart, C. L., Hole, D. J., and McMurray, J. J. (2002). A Population-Based Study of the Long-Term Risks Associated with Atrial Fibrillation: 20-year Follow-Up of the Renfrew/Paisley Study. Am. J. Med. 113, 359-364. doi:10. 1016/s0002-9343(02)01236-6

Sullivan, R. M., Zhang, J., Zamba, G., Lip, G. Y., and Olshansky, B. (2012). Relation of Gender-specific Risk of Ischemic Stroke in Patients with Atrial Fibrillation to Differences in Warfarin Anticoagulation Control (From AFFIRM). Am. J. Cardiol. 110, 1799-1802. doi:10.1016/j.amjcard.2012.08.014

The Japan Circulation Society (2014). Guidelines for Pharmacotherapy of Atrial Fibrillation (JCS2013). Circ. J. 78, 1997-2021. doi:10.1253/circj.cj-660092Available at: http://www.j-circ.or.jp/guideline/pdf/JCS2013_inoue_h.pdf (Accessed November 21, 2020).
The Japan Circulation Society/Japanese Heart Rhythm Society Joint GuidelinesOno, K., Iwasaki, Y., and Shimizu, W., (2020). JCS/JHRS 2020 Guideline on Pharmacotherapy of Cardiac Arrhythmias. Available at: https://www.j-circ.or.jp/cms/wp-content/uploads/2020/01/JCS2020_Ono.pdf (Accessed November 21, 2020).

The Japan Geriatrics Society (2015). Guidelines for Medical Treatment and its Safety in the Elderly 2015. Available at: https://www.jpn-geriat-soc.or.jp/info/ topics/pdf/20170808_01.pdf (Accessed November 21, 2020).

Toda Kato, E., Robert, P. G., Christian, T. R., Koretsune, Y., Yamashita, T., Robert, G. K., et al. (2016). Efficacy and Safety of Edoxaban in Elderly Patients with Atrial Fibrillation in the ENGAGE AF-TIMI 48 Trial. J. Am. Heart Assoc. 5, e003432. doi:10.1161/JAHA.116.003432

Tomita, H., Kadokami, T., Momii, H., Kawamura, N., Yoshida, M., Inou, T., et al. (2013). Patient Factors against Stable Control of Warfarin Therapy for Japanese Non-valvular Atrial Fibrillation Patients. Thromb. Res. 132, 537-542. doi:10. 1016/j.thromres.2013.09.003

van Walraven, C., Jennings, A., Oake, N., Fergusson, D., and Forster, A. J. (2006). Effect of Study Setting on Anticoagulation Control: a Systematic Review and Metaregression. Chest 129, 1155-1166. doi:10.1378/chest.129.5.1155

Vanassche, T., Verhamme, P., Wells, P. S., Segers, A., Ageno, W., Brekelmans, M. P. A., et al. (2018). Impact of Age, Comorbidity, and Polypharmacy on the Efficacy and Safety of Edoxaban for the Treatment of Venous Thromboembolism: An Analysis of the Randomized, Double-Blind Hokusai-VTE Trial. Thromb. Res. 162, 7-14. doi:10.1016/j.thromres.2017.12.005

Wan, Y., Heneghan, C., Perera, R., Roberts, N., Hollowell, J., Glasziou, P., et al. (2008). Anticoagulation Control and Prediction of Adverse Events in Patients with Atrial Fibrillation: a Systematic Review. Circ. Cardiovasc. Qual. Outcomes 1, 84-91. doi:10.1161/CIRCOUTCOMES.108.796185

Wolf, P. A., Abbott, R. D., and Kannel, W. B. (1991). Atrial Fibrillation as an Independent Risk Factor for Stroke: the Framingham Study. Stroke 22, 983-988. doi:10.1161/01.str.22.8.983

Conflict of Interest: The authors declare that the research was conducted in the absence of any commercial or financial relationships that could be construed as a potential conflict of interest.

Copyright (c) 2021 Takamoto, Sakamoto, Ito, Kimura, Manabe, Shikata, Asakura, Ishihara and Tsujino. This is an open-access article distributed under the terms of the Creative Commons Attribution License (CC BY). The use, distribution or reproduction in other forums is permitted, provided the original author(s) and the copyright owner(s) are credited and that the original publication in this journal is cited, in accordance with accepted academic practice. No use, distribution or reproduction is permitted which does not comply with these terms. 